\title{
Foreign and domestic expertise in strengthening concrete structures with carbon fiber
}

\author{
Dmitriy Topchiy ${ }^{1, *}$, and Egor Safenkov ${ }^{1}$ \\ ${ }^{1}$ Moscow State University of Civil Engineering, Yaroslavskoe shosse, 26, 129337, Moscow, Russia
}

\begin{abstract}
Over the last 10-15 years, Russia has faced a significant increase in the scope of reconstruction work (including restoration and overhaul) for buildings of various purposes aiming to extend the life cycle of existing facilities and to bring buildings in line with requirements of modern regulatory documents in terms of strength and increase in their energy efficiency. Strengthening the building structures with composite materials is by far the most 'gentle' method of restoring building structures and improving their operational performance. At the same time, there is only a small number of publications generalizing this type of strenghtening in the domestic scientific and technical literature. During the operation of buildings and structures (especially industrial ones) numerous factors cause accelerated degradation in building structures. This phenomenon is particulary strong in reinforced concrete structures due to their composite base. Practice shows that corrosive damage is one of the main factors of intensive constuction degradation of reinforced concrete structures. Therefore, these damages are caused by manufacturing defects (reduction of concrete protective layer), loss of concrete-against-reinforcement protective properties due to carbonization or damage. Corrosive damage greatly reduces the life capability and durability of reinforced concrete structures, which in turn leads to a decrease in the safety of construction site operations.
\end{abstract}

\section{Introduction}

This article aims to review and compare foreign and domestic expertise in strengthening reinforced concrete structures, as well as to review new materials and technologies not previously used in Russia.

\section{Materials and methods}

The use of composite materials as a repair measure may be illustrated by strengthening of the edge beam of berth $\# 9$ of the Novorossiysk sea port, performed by InterAqua and Portkomplex companies.

\footnotetext{
* Corresponding author: dvtopchiy0405@gmail.com
} 
The edge beam (Figure 1) is a pretensioned structure 12 meters long. 6 bunches of highduty wire diameter $5 \mathrm{~mm}$ class B11 are used as pretension reinforcement material. Each bunch consists of 24 wires. The transverse structural reinforcement is made of rods $14 \mathrm{~mm}$ AII. The longitudinal reinforcement is made of rods $10 \mathrm{~mm}$ AII.

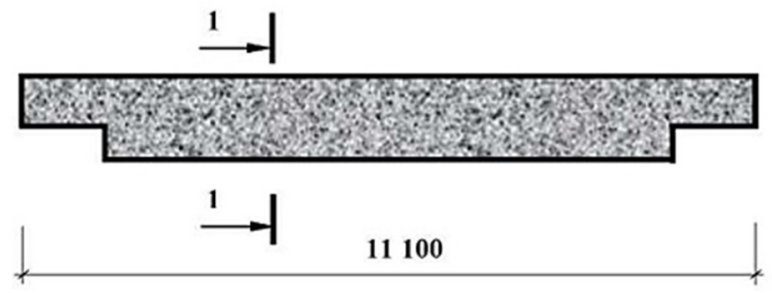

$\underline{1-1}$

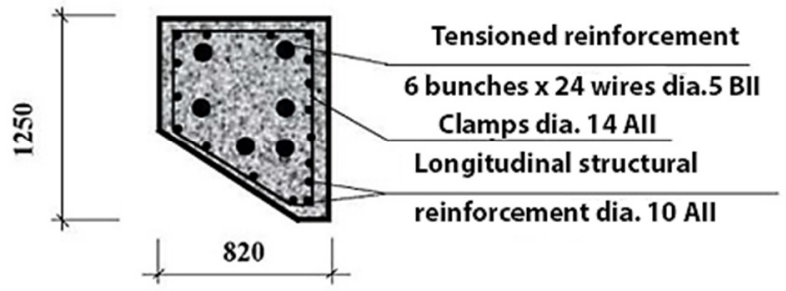

Fig. 1. Edge beam of temperature insert.

The examination found numerous detachments of concrete up to $8 \mathrm{~cm}$ in depth on the surface of the beam with stripping of longitudinal and transverse structural reinforcement (Figure 2). The expert estimation registered the $40 \%$ loss in cross section of structural reinforcement due to corrosion, no damage of pretensioned reinforcement was detected.

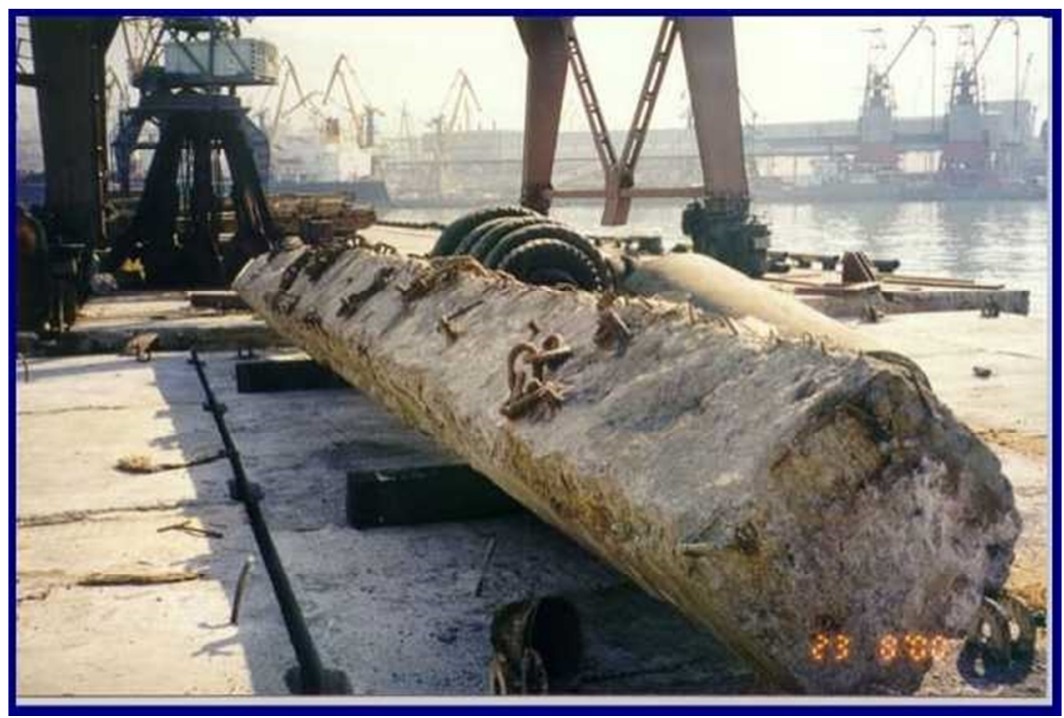

Fig. 2. Edge beam before the repair.

To compensate for the loss of structural reinforcement it was decided to stick domesticproduced carbon stripes LU-300-2.

Before adhering the stripes, repair and recovery works on the beam section were performed including the following: 
1. Cleaning of concrete surface, removal of regions with damaged structure,

2. Cleaning of stripped reinforcement from rust, its treatment with rust solvent,

3. Concrete surface treatment with corrosion inhibitor,

4. Concrete surface repair using special high-duty quick-hardening compositions (indent and cavities patching, surface leveling).

It is seen that structure preparation for repair and strengthening includes corrosionblocking operarations for reinforcement, while corrosion tends to progress with the earliest signs of destruction. If no such actions are foreseen, the corrosion products would tear off the protective layer from repair materials to cancel out any efforts of sticking the composites [1].

The base to stick the carbon stripe to should be minimum 1.5 MPa strong. This should be taken into account when selecting materials and technology for destructive surface repair, which provide high adhesion to the bottom layer. The repairing layer should provide a durable base to stick the reinforcing pads and to work with them merged.

Carbon stripes were stuck with special epoxy compositions. Before sticking the concrete surface was coated with a primer composition spread $0,8 \mathrm{~kg} / \mathrm{m} 2$. After that the stripes were cut to fit the sizes, then soaked with adhesive composition (spread 0.4-0.4 $\mathrm{kg} / \mathrm{m} 2$ ) and stuck by pressing to the concrete surface and then rolled through polyethylene film.

As per the estimates done, stripes $150 \mathrm{~mm}$ wide with stepd $150^{\wedge} 200 \mathrm{~mm}$ from 4 layers of carbon stripe are required to be adhered in longitudal and transverse direction to compensate the loss in structural reinforcement [2].

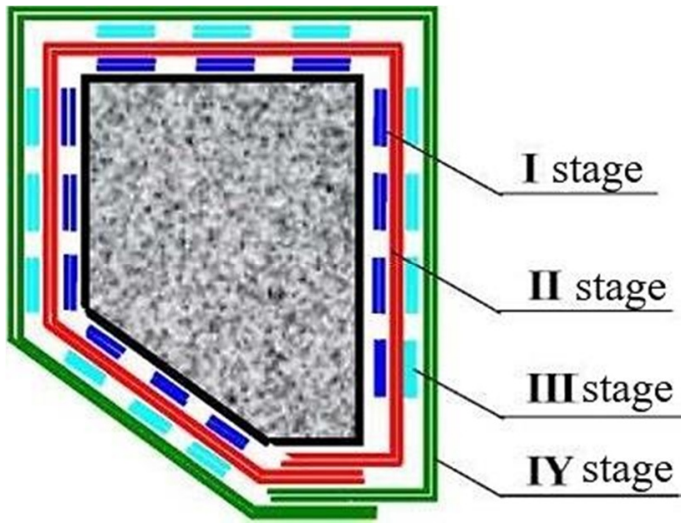

Fig. 3. Carbon stripes adhesion pattern.

Since carbon stripes LU-300-2 are $300 \mathrm{~mm}$ wide, they were folding in two when being adhered. At stage 1, 2 layers of longitudinal strips were adhered, at stage 2, it was 2 layers of transverse strips. The operations were repeated at stages 3 and 4 . The ambient temperature during the adhering was $20-22^{\circ} \mathrm{C}$, while epoxide polymerization process was being finished on the following day. After adhesion was completed, the stripes surface was finished with a protective epoxide composition with powdering small-scale quartz sand over the freshly-prepared surface. Figure 4 shows the edge beam during the carbon stripes adhering process. After being repaired and strengthened, the edge beam was mounted to the structure of the bearth. Operation within several months showed that the repair was satisfactory since neither damages in the repairing layer nor stripping-off of the carbon fiber strips occurred. 


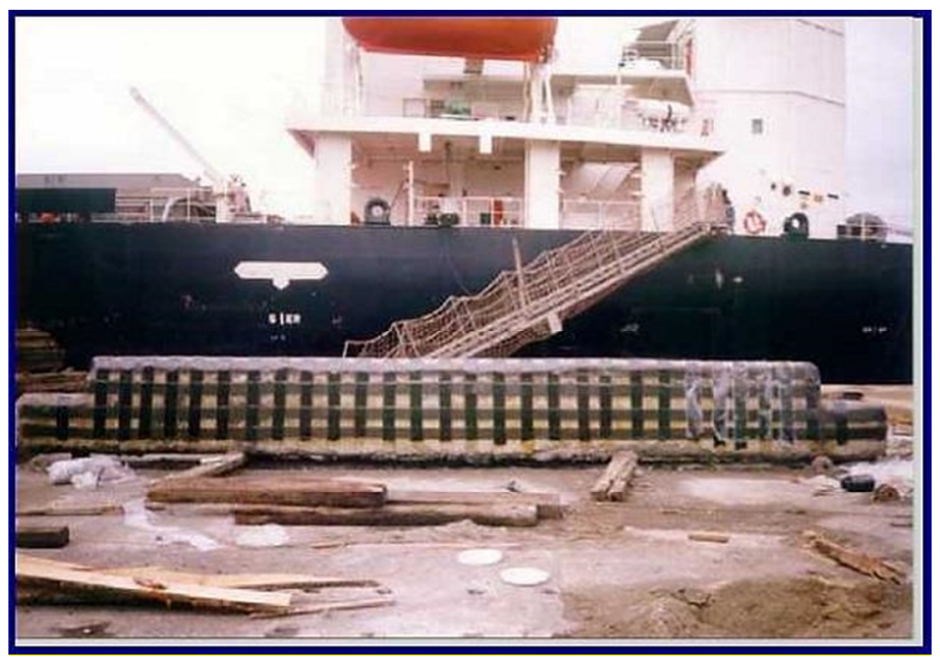

Fig. 4. The edge beam during the carbon stripes adhering process.

An integrated approach to structure repairing is illustrated by the repairing work on the thickener bowl at the 3rd mine administration of Silvinit Ltd in Solikamsk (Figures 5, 6).

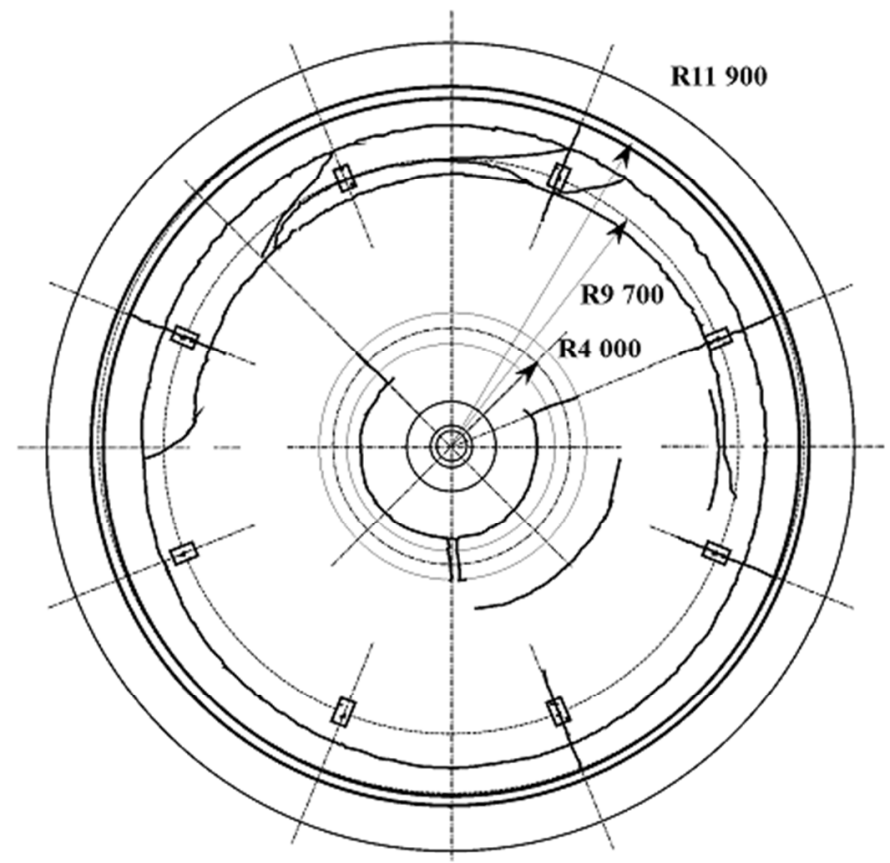

Fig. 5. Cracks arrangement on the inner surface of the bowl.

The reinforce-concrete bowl is designed to coagulate helitic wastes. The coagulation unit is a solid reinforce-concrete bowl-shaped cone-bottomed reservoir basing upon the central support and pillars along the perimeter of the peritheral support bar (fig 1).

The coagulation unit is made of M200 grade concrete. Working and structural reinforcements are made of AII class rods. 
A steel truss rests against the central support and against the annular rail along the bowl perimeter. Helitic wastes are mixed via scrapers hanging from the truss when the truss revolves [3].

The structural load consists of:

1. Weight of structural components $(0.72 \mathrm{t} / \mathrm{m} 2)$,

2. Process load of helitic wastes $(4.2-7.1 \mathrm{t} / \mathrm{m} 2)$,

3. Load of truss metal structure $(20 \mathrm{t})$.

An examination revealed numerous defects and damages - annular and radial cracks in the area of the support and central support (fig. 2), concrete delaminations up to $8 \mathrm{~cm}$ deep on the inner surface of the bowl, hidden cavities (areas making a dull sound when rapping), signs of reinforcement corrosion. Leakage of the process solution indicates the presence of throughwall cracks

Based on the examination results of defects and deformations of the coagulation unit spatial structure, computer simulation of the actual bearing capacity and deformability of structural components was performed. Strength and deformability calculations were performed with due account to the actual physicomechanical characteristics of concrete and reinforcement, the geometrical arrangement of the existing cracks, and data on uneven deformations of the coagulation unit [4].

The computer simulation results allowed to identify (figure 3) that the areas of maximum tensile stress in concrete with a fixed position of the movable truss have a width of about 1.5-3.0 meters and are located both above the central support and above the annular support beam. The absolute value of tensile stresses is $76.34 \mathrm{kgf} / \mathrm{cm}^{2}$ which is 7 times above the limit strength of concrete according to the $\operatorname{SNiP}\left(10.7\right.$ carbon $\left.\mathrm{kgf} / \mathrm{cm}^{2}\right)$. This accounts for the formation of annular cracks in the area of central support and along the perimeter of the annular support beam. Considering the movement of movable truss, the dimensions of critical stressed areas propagate along the entire perimeter of the bowl.

The area of dangerous concentrations of tensile stresses on the bottom surface of the bowl is located in the central span between the annular support beam and the central support. In general, the results of computer simulation predict the formation of a complex spatial pattern of cracks, which matches the actual state.

The formation of cracks and other defects in the coagulation unit's bowl is likely to be caused not only by the designed loads, but also by such adverse factors as uneven foundation settlement, aggressive effects of halitic waste, etc. [5].

Based on the analysis of distribution of the maximum stress areas, the scheme was developed to strengthen the coagulation bowl with high-strength carbon fiber (Figure 6). 


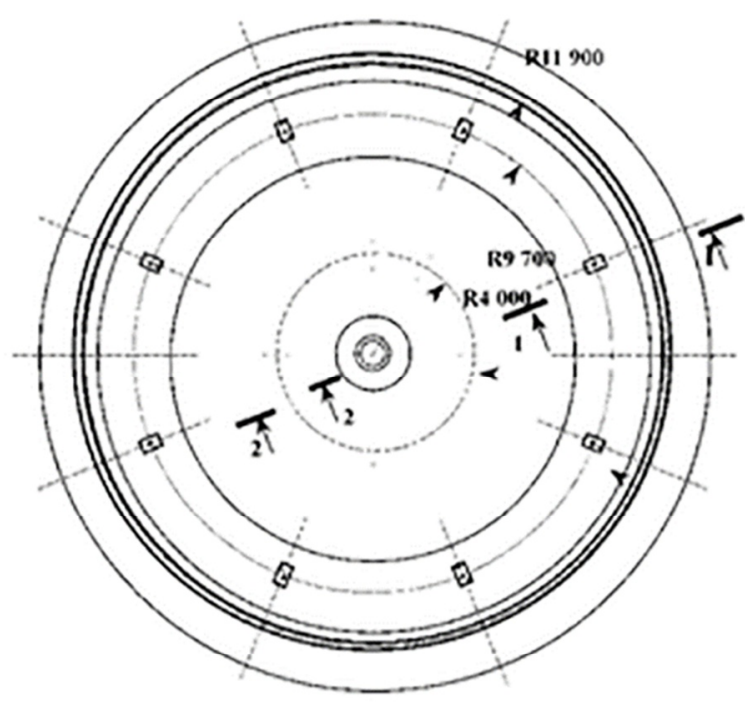

Overlay in the central support area

Overlay in the annular beam area
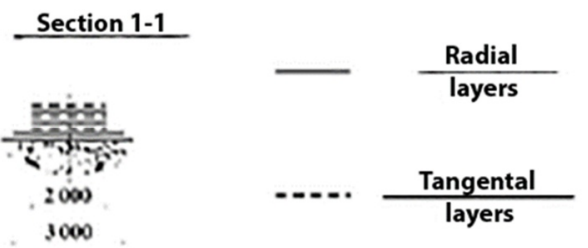

Section 2-2

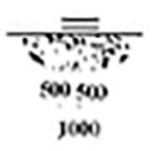

Fig. 6. Bowl strengthening with carbon fiber strips.

The carbon-fiber overlays act as external reinforcement and are formed by adhering carbon stripes to the bowl's surface using special epoxy compounds. The carbon fibers content in the composite is about $60 \%$, the main physicomechanical properties of the carbon fiber after polymerization are as follows:

1. Tensile strength $-1450 \mathrm{MPa}$

2. Modulus of elasticity $-126,000 \mathrm{MPa}$

3. Elongation at break $-0.8 \%$

The calculations showed that in order to restore the bearing capacity of the structure, it is necessary to stick the carbon fiber in two areas along the inner surface of the coagulation bowl:

1. Along the perimeter of the support beam

2. In the area about the central support

The overlay in the area of the annular support beam must consist of six monolayers of stripe, three of which are laid in the radial direction and three in the tangential one. The width of the lower radial layer is $3 \mathrm{~m}$, the two following ones are $2 \mathrm{~m}$ each. The width of all 3 layers of the tangential overlay is $2 \mathrm{~m}$ each.

Annular overlay in the area of the central support with radius of $4 \mathrm{~m}$ is made of two radial layers $1 \mathrm{~m}$ wide each.

Metal dowels were fixed to determine the deformations of the bowl at 10 points of the lower surface of its bottom and at the top points of 5 support columns. Metal roulettes with millimeter graduations were suspended to the dowels. The deformation values were determined by leveling and calculating the difference in the levels of the dowels. The 
difference of similar dowels corresponds to the vertical deformations of the bowl's bottom points and supporting columns' points, where the dowels are fixed. The dowels' levels were oriented in the relative system of heights agaings three reference points located outside the bowl's load area.

The leveling of deformation points and reference points was carried out 9 times by the same arrangement with different filling volumes of the bowl with saline solution.

The first leveling cycle was performed before the primary filling of the bowl. Cycle 2 after filling the bowl at $1 / 3$ volume with a load of 420 tons. Cycle 3 - after filling the bowl at $2 / 3$ volume with a load of 840 tons. Cycle 4 - after filling the bowl to the full, which corresponds to a load of 1260 tons. Cycle 5 is performed after complete emptying of the bowl [6].

\section{Research result}

The computer modeling of the coagulation unit' spatial structure strength, with respect to the strenghening, shows that tensile stresses in concrete do not exceed $5 \mathrm{kgf} / \mathrm{cm} 2$, which is 2 times lower than the standard SNiP value (10.7 kgf / cm2) [7].

Sticking of carbon stripes was preceded by reinforcement corrosion-blocking operation as well as repair and restoration of the structure's cross section. Corrosion blocking of reinforcement is vital since otherwise the corrosion products would tear off the protective layer from repair materials to cancel out any efforts of sticking the composites. No less important is the strength of the base ( of the protective layer) on which the carbon stripes are applied [8]. The tensile strength of concrete should be at least 1.5 MPa. This should be taken into account when choosing materials and technology for repairing a destructive surface to provide high strength and adhesion to the bottom player.

The process of applying the carbon stripes is shown on figures 7 and 8 .

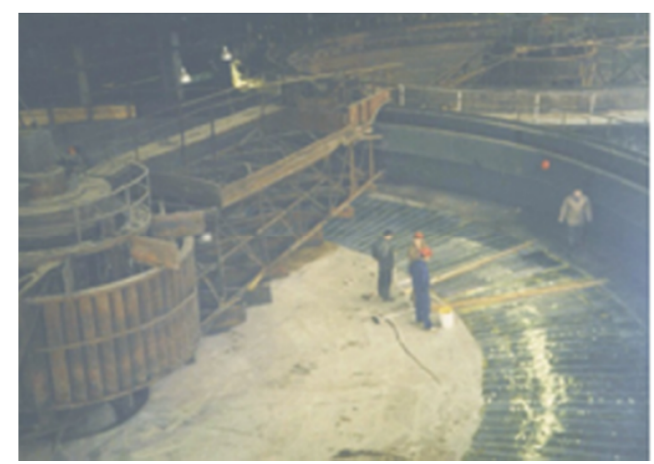

Fig. 7. Overall view of the coagulation unit during the strengthening. 


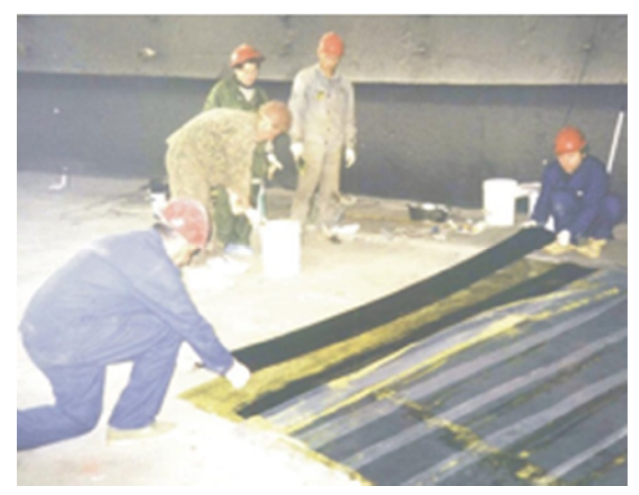

Fig. 8. Radial stripes being applied.

After applying all of the carbon-stripe layers, the overlays' surfaces were coated with AE-1 compound. The remaining part of the bowl surface was covered with a layer of chlorosulfonated polyethylene in order to protect it from halitic solutions.

To assess the degree of rigidity and quality of the bowl's watertightness after the repair works, tests were performed by filling the bowl with a saline solution with a specific weight of $1.23 \mathrm{~g} / \mathrm{cm} 3$. The deformability is estimated by precise geometric leveling of some points on the bowl's bottom and on the columns [9]. The leveling scheme is shown in Figure 10.

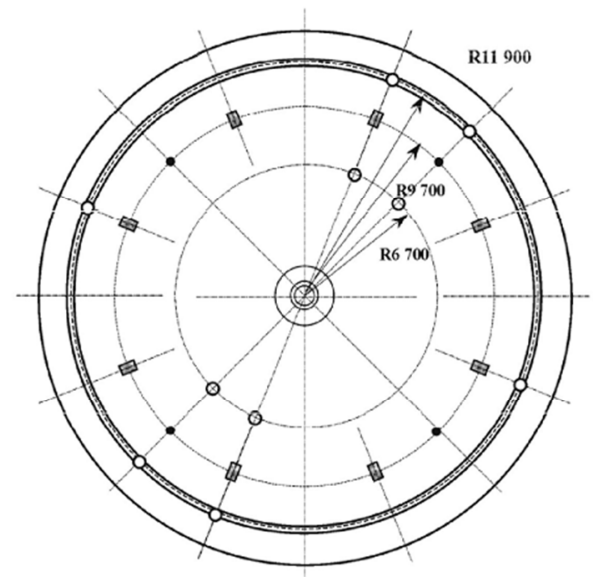

Fig. 9. Leveling arrangement: $\bullet-$ dowels in the columns; ${ }^{\circ}-$ dowels in the bowl's bottom.

\section{Conclusion}

As a result, deformations of the bowl at maximum loads did not exceed $4 \mathrm{~mm}$, which is more than 2 times lower than expected. No leakage and waterproofing damages were recorded [10].

The following operation of the coagulation unit within several months showed that the repair quality is good - no destruction of the repair layer and no delaminations of the carbon fiber occured.

To sum up, it can be concluded from the results of the work performed that the use of composite materials may lay foundations to the new trend in reconstructing reinforced 
concrete engineering structures to provide a significant reduction in labor intensity, cost, and performance time [10].

Developing the present topic, we managed to arrange the organizational and technological order of works on strengthening of reinforced concrete structures with composite materials, using the examples from domestic and foreign expertise. These technologies for strengthening reinforced concrete structures with carbon fiber were originally taken from foreign expertise and have been gradually gaining momentum in Russia. However, the process goes here much slower than in the Western world, mainly because of the relative expensiveness of such work, but I still think that everyone would recognise the great advantages of the technology over time and would prefer it to alternative methods.

\section{References}

1. D.D. Zueva, E.S. Babushkin, D.V. Topchy, A.Yu. Yurgaitis, MATEC Web of Conferences 265, (2019). DOI: 10.1051/matecconf/201926507022.

2. D. Topchiy, E. Kochurina, MATEC Web Conf 193, (2018). DOI:10.1051/matecconf $/ 201819305012$

3. I. Abramov, T.Poznakhirko, A. Sergeev, MATECWebConf 86, (2016). DOI:10.1051/matecconf $/ 20168604063$

4. D. Topchiy, A. Tokarskiy, MATEC Web Conf 196, (2018). DOI:10.1051/matecconf/201819604029

5. D. Topchiy, A. Yurgaytis, E. Babushkin, D. Zueva, MATEC Web Conf. 265, (2019). DOI: $10.1051 /$ matecconf/201926507022.

6. A.S. Bolotova, A.A. Zelentsov, A.S. Vorobev, D.V. Topchiy, A.V. Atamanenko, International Journal of Civil Engineering and Technology 2, 2160-2166, (2019).

7. A.A. Lapidus, I.L. Abramov, IOP Conference Series: Materials Science and Engineering 3rd World Multidisciplinary Civil Engineering, (2019). DOI: 10.1088/1757-899X/603/5/052079.

8. A. Lapidus, I. Abramov, MATEC Web of Conferences, (2018). DOI:10.1051/matecconf/201825105017.

9. V. Klimina, A. Yurgaitis, D.V. Topchiy, E3S Web of Conferences, (2019). DOI:10.1051/e3sconf/201911001086.

10. D.V. Topchy, A.A. Lapidus, "E3S Web of Conferences", (2019). DOI:10.1051/e3sconf/20199108044. 